\title{
Modular Power Converters for PV Applications
}

May 2012

Prepared by

B. Ozpineci

L. Tolbert

Oak Ridge National Laboratory 


\title{
Modular Power Converters for PV Applications
}

\author{
Prepared for the \\ The University of Tennessee \\ Center for Industrial Services \\ 193C Polk Avenue \\ Nashville, TN 37210 \\ Principal Authors \\ Burak Ozpineci and Leon Tolbert
}

May 2012

\section{Prepared by}

OAK RIDGE NATIONAL LABORATORY

Oak Ridge, Tennessee 37831-6070

managed by

UT-BATTELLE, LLC

for the

U.S. DEPARTMENT OF ENERGY

under contract DE-AC05-00OR22725 


\title{
Modular Power Converters for PV Applications
}

\section{Objective:}

This report describes technical opportunities to serve as parts of a technological roadmap for Shoals Technologies Group in power electronics for PV applications.

\begin{abstract}
There are many different power converter circuits that can be used for solar inverter applications. The present applications do not take advantage of the potential for using common modules. We envision that the development of a power electronics module could enable higher reliability by being durable and flexible. Modules would have fault current limiting features and detection circuits such that they can limit the current through the module from external faults and can identify and isolate internal faults such that the remaining modules can continue to operate with only minimal disturbance to the utility or customer.
\end{abstract}

Development of a reliable, efficient, low-cost, power electronics module will be a key enabling technology for harnessing more power from solar panels and enable plug and play operation.

\section{Scientific/Technical Goal and Opportunity}

Power electronics for computer power supplies, communication equipment, and transportation have all targeted reliability and modularity as key requirements and have begun concerted efforts to replace monolithic components with collections of common smart modules. This is happening on several levels including 1) device level with intelligent control, 2) functional module level, and 3) system module. This same effort is needed in power electronics for solar applications.

Development of modular units will result in standard power electronic converters that will have a lower installed and operating cost for the overall system. These units will lead to increased adaptability and flexibility of solar inverters. Incorporating autonomous fault current limiting and reconfiguration capabilities into the modules and having redundant modules will lead to a durable converter that can withstand the rigors of solar power generation for more than 30 years.

Our vision for the technology roadmap is that there is no need for detailed design of new power converters for each new application or installation. One set of modules and controllers can be pre-developed and the only design question would be how many modules need to be in series or parallel for the specific power requirement. Then, a designer can put the modules together and add the intelligent reconfigurable controller. The controller determines how many modules are connected, but it might also ask for user input for the specific application during setup. The modules include protection against faults and can reset it, if necessary. In case of a power device failure, the controller reconfigures itself to continue limited operation until repair which might be as simple as taking the faulty module out and inserting a new module. The result is cost savings in design, maintenance, repair, and a grid that is more reliable and available. This concept would be a perfect fit for the recently announced funding opportunity announcement (DE-FOA0000653) on Plug and Play Photovoltaics. 


\section{Background and Approach}

In addition to providing real power to meet local load demands, distributed generation (DG) from solar power can be used to provide services such as voltage regulation, frequency regulation and reactive power supply, among others. This will be critical for DG to increase the reliability of the local distribution system. The power electronics will help maintain local voltage and frequency within normal operating range regardless of outside stresses on the grid. Another critical element of the power electronics is that it should have the necessary protection features and fault current limiting capabilities such that the existing conventional distribution protection schemes do not have to be redesigned or recalibrated.

Previously, different government programs have worked on modularizing power electronics. As a result of their work, some module concepts have been developed; however, they have not been widely accepted. The main reason for this was that those programs targeted to build the best power device with all the functions and protection schemes. The devices themselves did not perform any conversion functions. In some cases, the programs depended on specific kind of novel power device concepts. The programs died out as the promised developments in the specific device did not go as expected.

The technical roadmap should include the development of a family of universal modular converter blocks and a suite of multifunctional control that will be used for a wide variety of applications, mainly focusing on an interface with photovoltaics. These modules will need a universal controller that should be programmed for a wide variety of functions depending on the application need. In addition to regulating real power flow, the controller will allow reactive power control, voltage regulation, frequency regulation, harmonic compensation, and damping of transients. In one of our approaches, the individual modules will be functional by themselves. The modules can be built using any present or future power device and they do not depend on certain types of power devices.

In addition, the modules will have fault current limiting capabilities such that currents through these converters are inherently clamped and limited to allowable current values. The modules will also be designed such that they will have autonomous internal fault detection and reconfiguration such the failure of a single module can be easily identified and isolated such that the remaining modules in a converter installation can continue to operate and provide the services and functions required by the utilities and customers.

Several advantages that this universal module will have over the traditional customized converter design include:

- Increased reliability: When one module fails, the system can reconfigure itself online to continue operation with the operable units until the faulted module is replaced.

- Reduced cost: Producing standard modules decreases the manufacturing costs as opposed to custom designs. This will make solar installations more economically feasible.

- Maintainability: Modules can be replaced easily and the downtime is reduced. This increases the availability of power. 
- Increased lifetime: A robust, standardized design will be developed and thoroughly tested so that lifetimes on the order of decades, like other utility equipment, can be achieved, and spare parts will be readily available. The equipment will not become obsolete and not repairable in a few years as conventional converters do.

- Modularity and scalability. More modules can be easily added in parallel to increase current carrying capacity or in series for higher voltage applications.

- Energy storage and backup power interface: Adding energy storage (capacitors/batteries) is as convenient as adding another module together with an energy storage device.

- Remote control from a central control area is possible as well as local control to allow the unit to run autonomously.

One of the devices that will be examined for use in the module for fault current limiting will be the silicon carbide (SiC) junction field effect transistor (JFET). This is a normally-on device; therefore, no energy is required to keep it on for normal operation. A SiC JFET has a positive temperature coefficient which means that its on-resistance will increase with temperature. This self-heating feature would be the first mechanism to inherently limit the current in real time as it increases during a fault.

In power electronics applications, a JFET is used as a switch that turns on and off. In low power electronics, a JFET can also be used as an amplifier and/or a gate-controlled variable resistor. For this project, we are proposing a controller for a high voltage SiC JFET that will detect a fault condition fast and adjust the gate drive of the JFET to limit the fault current in addition to the self-heating phenomenon. Figures 1 and 2 show self-heating effect of the SiC JFET. As the device temperature increases, its on-resistance increases and the device limits the current. Figure 3 shows how the amount of current allowed through the device can be reduced by varying the gate voltage. Figure 4 shows the high surge current capability of a SiC JFET.

The fault current limiting power electronics module will have following advantageous attributes:

- Fast response (in ms) so that the line does not see the first peak of the fault current. The peak current will be reduced to a fraction of the normal full fault value because of the introduced resistance.

- Since the peak fault current is limited, other circuit components in the utility system such as conductors and circuit breakers do not have to be derated.

- No flammable liquids such as oil or SF6 are required. The resulting device is environmentally safe.

- Longer lifetime - by limiting fault current in the module - it will help allow the power electronics converter to come closer to achieving the desired lifetime of 30 to 50 years that other electrical equipment has achieved in the electrical system.

- Longer lifetime for transformers since high fault currents will not flow through them.

- For reliability, redundant modules can be incorporated.

- No switching during steady-state operation.

- High temperature operation; therefore, air-cooling can be used rather than liquid cooling; therefore associated coolant and pump can be eliminated. Air cooling is generally deemed to be more reliable than liquid cooling provided the power electronics devices are operated 


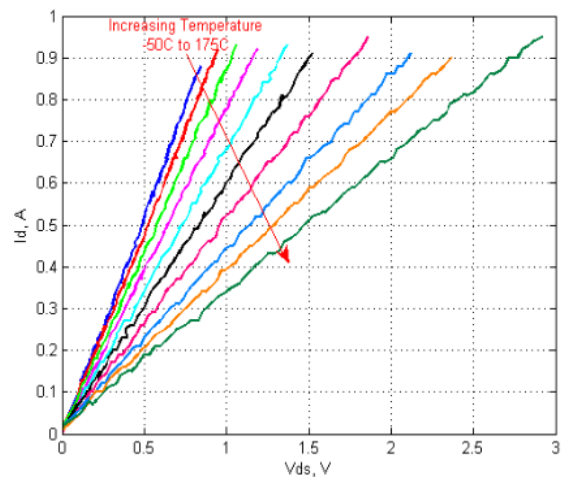

Fig. 1. Static $i-v$ characteristics of SiC JFET at different temperatures.

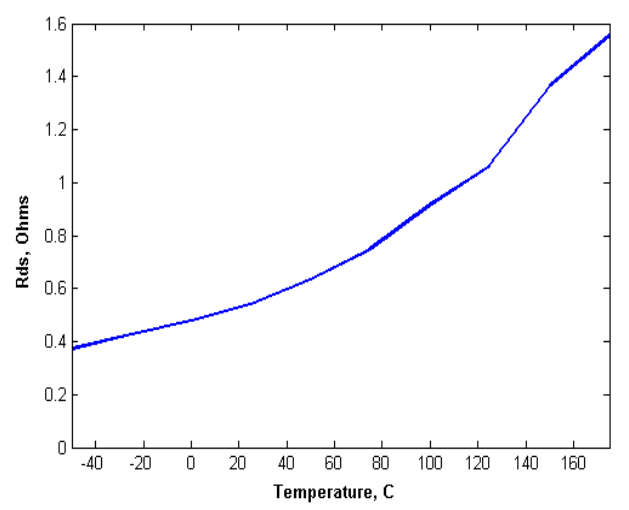

Fig. 2. When high current flows through a JFET, it starts heating up (self heat) and its on resistance increases.

below their rated junction temperature. SiC devices will allow the devices to operate at much higher junction temperature than present silicon-based power electronic devices. 


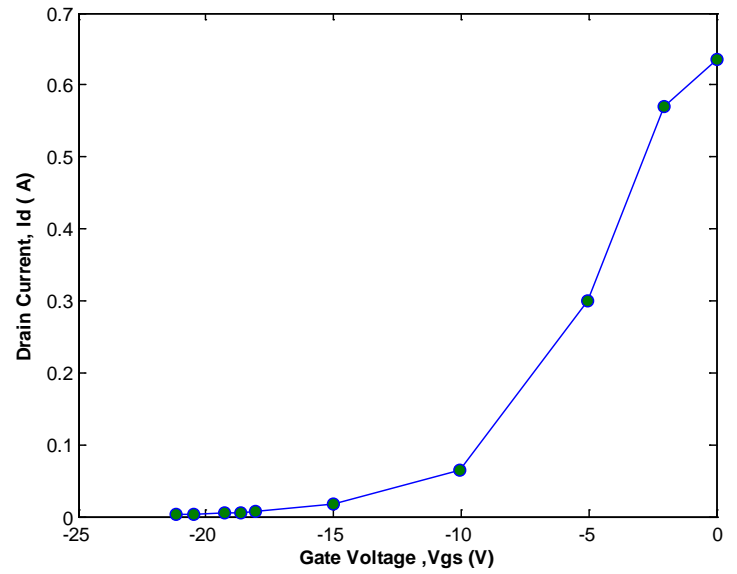

Fig. 3. As the gate voltage is decreased from 0 to -25 , the drain current is reduced. The switch acts like a valve being turned off.

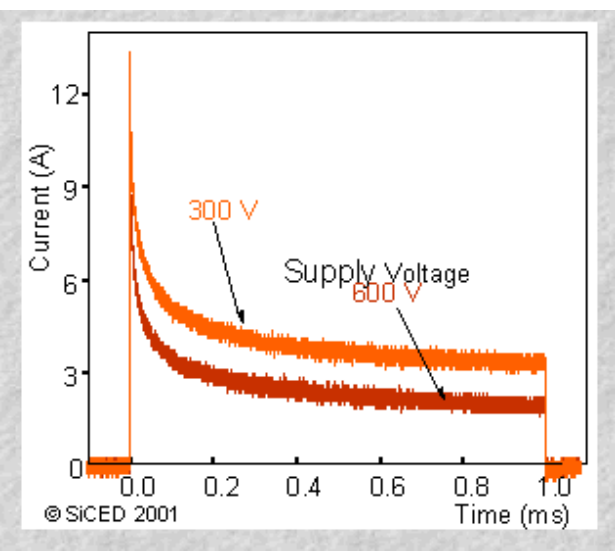

Fig. 4. SiC JFET Manufacturer: "In the case of a short circuit our VJFETs are automatically protecting themselves by temperature dependent current saturation. This gives them short circuit protection in the order of milliseconds compared to 2 orders of magnitude less for Silicon switches (10 $\mu \mathrm{s})$ - excellent robustness and considerably reduced costs and effort for protection circuits”

\section{Technical Roadmap}

Module research and development

A candidate topology for demonstration purposes needs to be selected and a family of modules designed. Two examples of modular cells are 1) $\mathrm{N}$ or $\mathrm{P}$ cells (a novel building block developed by ORNL and UT) and H-bridge cells. Figure 5 shows how a bidirectional switch can be built using the $\mathrm{N}$ and $\mathrm{P}$ cell approach. While these modules look fairly simple, this is just a notional approach to give an example of what may be considered. In actuality, the circuits shown in Figure 5 are not typical connections of switches and diodes and differ from what is available from manufacturers today. However, this approach may be able to lead to new circuit topologies that have reduced voltage and current ripple and allows several different types of modules to be developed. Figures 6 and 7 show how a multilevel and a current source inverter can be designed using these basic cells. 


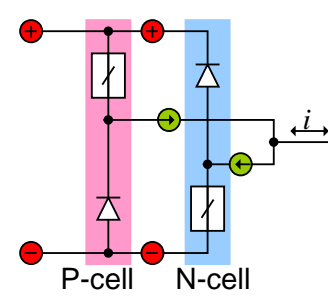

(a)

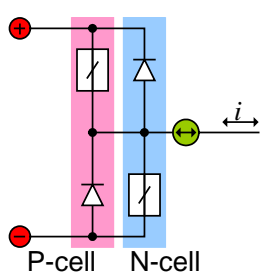

(b)

Fig. 5. A phase leg with bidirectional current flow by paralleling the $\mathrm{P}$ - and $\mathrm{N}$-cells.

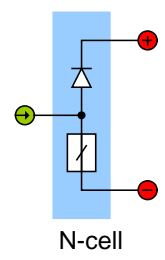

(a)

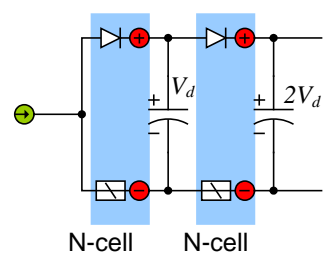

(b)

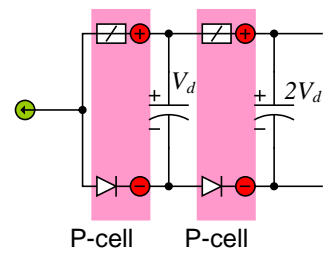

(c)

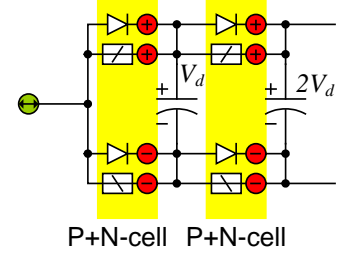

(d)

Fig. 6. A multilevel converter by paralleling the P- and Ncells.

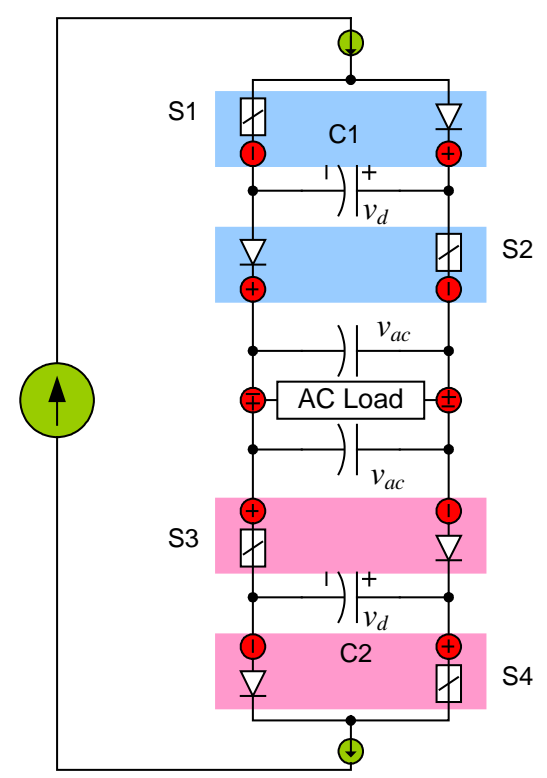

Fig. 7. Current source inverter constructed from series combination of P-cell and N-cell shown in Fig. 1.

A second potential approach uses an independently functional module to be used to build more advanced converters. A preferred configuration would utilize an H-bridge, two of which can be connected in parallel as shown in Figure 8a to form a three-phase inverter as shown in Figure 8b. In this case, $\mathrm{a}_{1}, \mathrm{~b}_{1}$, and $\mathrm{a}_{2}$ leads are connected to the three-phases. As opposed to the conventional three-phase inverters that have three phase-legs; the three-phase inverter formed by combining 
two H-bridges has four phase-legs. The fourth leg can be connected to the neutral for advanced control to eliminate the imbalances or it can be used as a dynamic brake/chopper to regulate the dc-link voltage. The third option is to use it as a spare phase leg to be used in case one of the other phase legs fail. If a whole module fails, it can be replaced with a spare one in stock.

If several H-bridges are connected in series as shown in Figure 9, one phase of a cascaded multilevel inverter would be formed. This configuration can be used to aggregate PV sources or can be used in a lot more utility applications.

The examples given above might look straightforward but the challenging research is in the details. As a part of this task, different module topologies need to be researched to find the best topology for modular power electronics. It should also include research to determine the most optimum voltage and current ratings and select the devices and components needed for utilityscale power electronics modules. This is an important aspect because a unit must be selected to be small enough to fit all solar applications.

Packaging requirements and thermal issues for the module also need to be considered. The packaging must protect the module and at the same time be proficient in conducting heat away from the lossy devices to the exterior of the package. Simulations can be used to make estimates of the power losses and make a judgment on the thermal management needs for the module to be reliable and survive the thermal, vibration, and voltage stresses that it will experience.

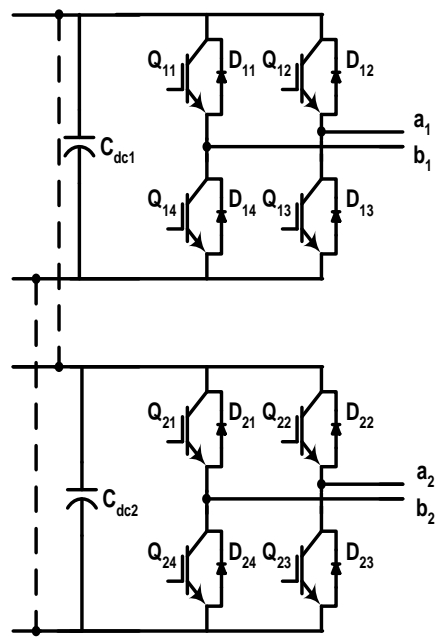

(a)

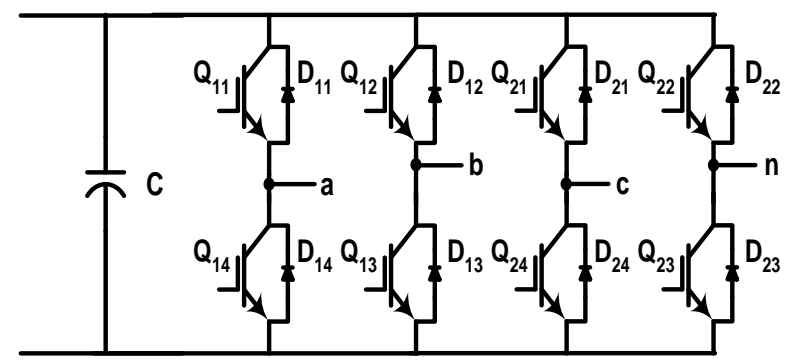

(b) 
Fig. 8. (a) The connection of H-bridges to form a three-phase inverter.

(b) The three-phase inverter formed using two H-bridges.

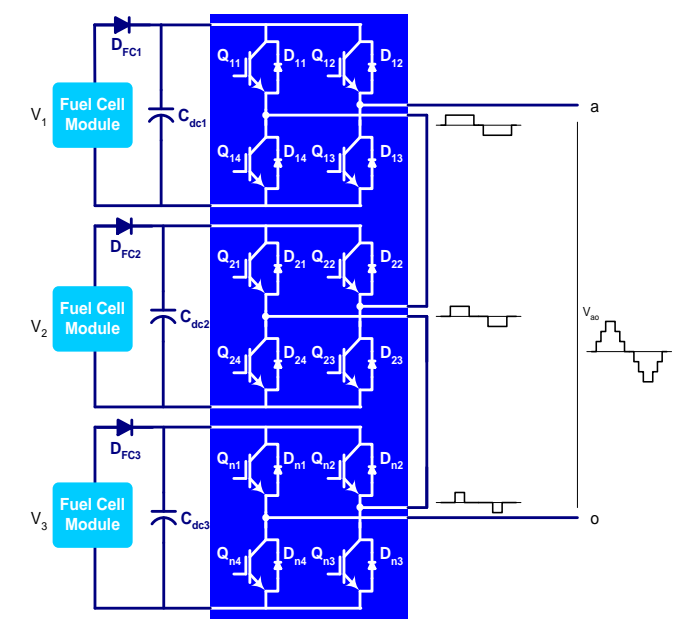

Fig. 9. 7-level cascaded multilevel inverter connected to multiple PV modules as an interface with the utility.

\section{Converter arrangements and utility interface}

A modular converter technology is needed that can be scaled up to distribution and transmission voltage and power levels to allow direct interconnection between the converter and utility (no transformer). Various circuit topologies can be developed from some modular cells and their performance in various applications can be simulated when connected in a utility environment.

\section{Module controller function definitions}

The final module needs to be multifunctional and pre-programmed with a suite of control algorithms so that it can be capable of performing different power control and power quality/reliability improvement tasks as commanded in real-time: power flow control, voltage regulation, instability damping, power factor correction, active filter for harmonics, sag compensation, or frequency regulation. Several possibilities exist for controlling power electronics modules including digital signal processors (DSPs), field programmable gate arrays (FPGAs) and application specific integrated circuits (ASICs), as well as personal computer with digital/analog interface card. One activity in this task should be to select the control method that can be easily integrated into a module and that will easily allow communication with other modules.

The controller has to be able to detect how many modules are connected to the system and decide how to use each one depending on the application (input by the user). If more modules are added, removed, or one or more modules fail, the controller will be able to reconfigure itself to be able to function at the maximum allowable capacity of the remaining modules. More detail on the reconfiguration ability is discussed next. 
This task includes several activities for the development of a fault current limiting module and reconfiguration capabilities in the event of an internal fault.

The first activity should be the design the fault current limiter and its controller. A low-power proof-of-concept prototype has to be built to verify the operation. Even though the device starts limiting the current automatically using self-heating, the controller should still be engaged when the fault current is identified. The present fault current identification techniques are not fast enough. New research is required to improve the fault current detection speeds. The reliability of the SiC JFET device for frequent surge currents has to be studied using simulations and experiments by modeling the reliability of the power switches for repeated surge currents. Using these and the device operation models, the ways to improve the reliability of the fault current limiting function of the module can be identified.

An intelligent reconfiguration technique that incorporates a self-diagnostic system based on neural networks and/or genetic algorithms can be proposed for the utility-connected converter composed of modular blocks. It is difficult to diagnose a multi-modular system using a mathematical model because the converter will consist of many switching devices and its system complexity has a nonlinear factor. Therefore, a neural network (NN) classification can be applied to the fault diagnosis of the converter system. Multilayer perceptron networks is a great option to identify the type and location of occurring faults. Principal component analysis (PCA) can be utilized in the feature extraction process to reduce the NN input size and only consider relevant data for determining which device or module may have had a failure. A lower dimensional input space will also usually reduce the time necessary to train a $\mathrm{NN}$, and the reduced noise may improve the mapping performance. Figure 10 shows a schematic of the proposed fault diagnosis system. The output phase voltage of the converter can be used to diagnose the fault type and their exact locations. As shown in Figure 11, faults in different parts of the system will likely yield voltages that can be distinguished from one another. The challenge is to have the modules and converter to autonomously identify the fault type and location without human intervention.

A reconfiguration technique can also be proposed that will be similar to that shown in Figure 12. The effects on voltage and current quality of using the proposed reconfiguration technique can be evaluated for several different modulation indices. The reconfiguration must be done in just a few cycles to as little as one cycle in order to limit the disturbance to the utility system. This is a highly challenging requirement to make measurements, determine fault type and location, and then perform some action to bring the system back to a normal operating state in only a few milliseconds. 


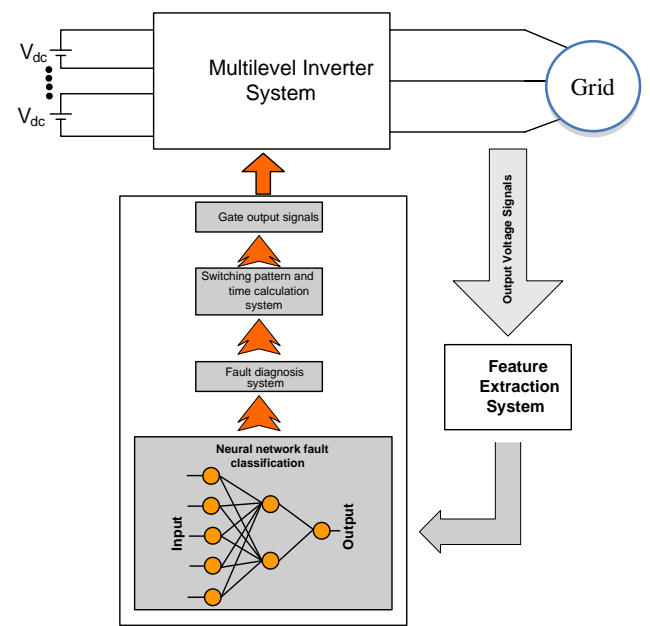

Fig. 10. Structure of fault diagnosis system.

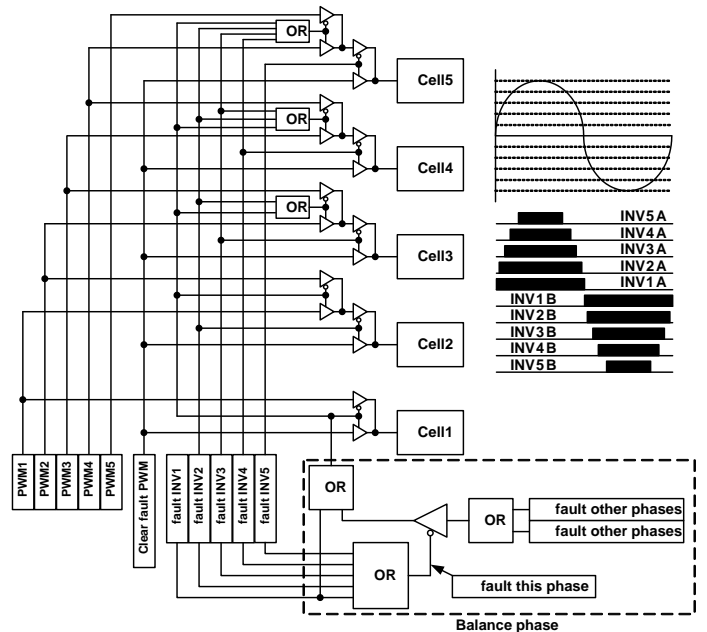

Fig. 11. Reconfiguration diagram for multi-modular converter system. 


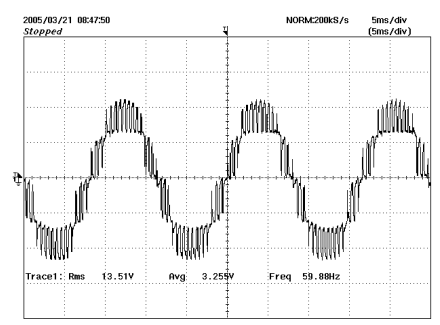

(a)

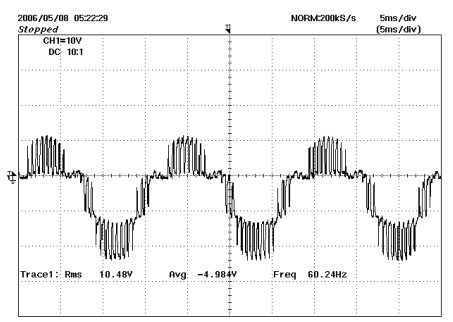

(b)

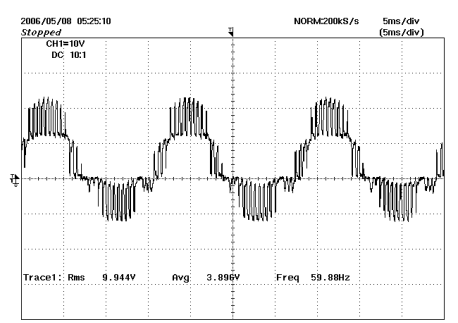

(d)

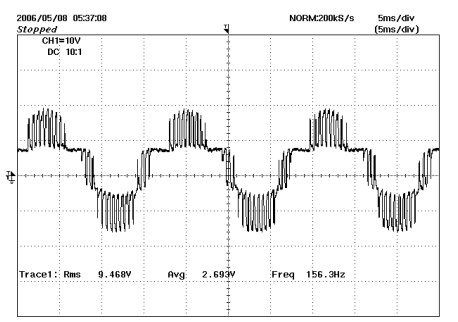

(c)

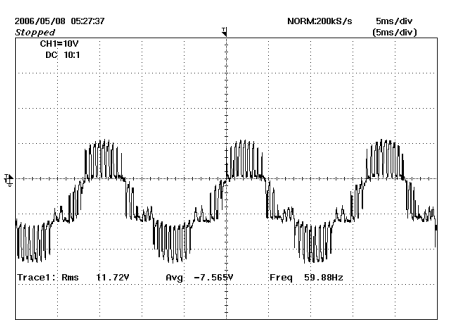

(e)

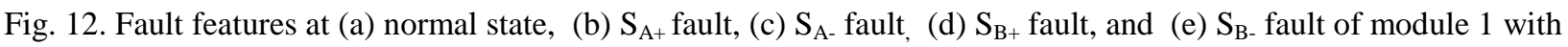
modulation index $=0.8$ out of 1.0 .

\section{Summary}

Shoals Technologies Group is a global leader in the balance of systems for PV. This report describes the technical vision The University of Tennessee and Oak Ridge National Laboratory researchers working in the PV power electronics area including technical tasks that need to be completed to propel Shoal to be global leader in PV power electronics. 


\begin{tabular}{|c|}
\hline \multicolumn{1}{|c|}{ Technical Roadmap Summary } \\
\hline Module Research and Development \\
\hline Identify target voltage, current ratings and select devices \\
\hline Determine circuit configuration \\
\hline Determine packaging and thermal management requirements \\
\hline \\
\hline Converter Arrangements and Utility Interface \\
\hline Assess utility requirements \\
\hline Examine possible converter topologies and arrangements \\
\hline Determine protective and communication features needed \\
\hline \\
\hline Module Controller Function Definitions \\
\hline Define possible functional states and controller needs of module \\
\hline Select controller and program requirements (DSP, FPGA, PC) \\
\hline \\
\hline Fault Current Limiting and Reconfiguration \\
\hline Evaluate and test materials for fault current limiting capabilities \\
\hline $\begin{array}{c}\text { Research fault identification algorithms from current/voltage } \\
\text { waveforms }\end{array}$ \\
\hline Research redundancy needs and reconfiguration techniques \\
\hline
\end{tabular}




\section{References}

[1] H. Akagi, "Prospects of New Technologies for Power Electronics in the 21st Century," Transmission and Distribution Conference and Exhibition 2002: Asia Pacific, Proceedings of the IEEE/PES, Vol. 2, Oct. 6-10, 2002, pp. 1399-1404.

[2] F.C. Lee, "The State-of-the-Art Power Electronics Technologies and Future Trends,” Power Engineering Society Summer Meeting, 2000. IEEE Proceedings, Vol. 2, July 16-20, 2000, pp. 12291232.

[3] L. M. Tolbert, F. Z. Peng, T. G. Habetler, “A Multilevel Converter-Based Universal Power Conditioner,” IEEE Transactions on Industry Applications, vol. 36, no. 2, Mar./Apr. 2000, pp. 596603.

[4] X. Yu, L. M. Tolbert, “Ancillary Services Provided from DER with Power Electronics Interface,” IEEE Power Engineering Society General Meeting, June 18-22, 2006, Montreal, Canada.

[5] J. B. Campbell, T. J. King, B. Ozpineci, D. T. Rizy, L. M. Tolbert, X. Yu, Y. Xu, “Ancillary Services Provided from DER,” ORNL/TM-2005/263, Oak Ridge National Laboratory, December 2005.

[6] S. Atcitty, S. Ranade, and A. Grey-Fenner, Summary of the State-of-the-art Power Conversion Systems for Energy Storage Applications, SAND98-2019, Sandia National Laboratories, September 1998.

[7] S. Atcitty and W.I. Bower, Power Electronics: Workshop on System Driven Approach for Inverter R\&D, April 23-24, 2003, Sandia National Laboratories, 2003.

[8] Standard for Interconnecting Distributed Resources with Electric Power Systems, IEEE Standard 1547, IEEE, Piscataway, NJ, 2003.

[9] B. Ozpineci, L. M. Tolbert, D. J. Adams, “Trade Study on Aggregation of Multiple 10-kW Solid Oxide Fuel Cell Power Modules,” ORNL/TM-2004/248, Oak Ridge National Laboratory, November 29, 2004.

[10] B. Ozpineci, L. M. Tolbert, "Comparison of Wide Band Gap Semiconductors for Power Electronics Applications,” ORNL/TM-2003/257, Oak Ridge National Laboratory, December 12, 2003.

[11] R. Chokhawala, B. Danielsson, L. Angquist, "Power Semiconductors in Transmission and Distribution Applications,” ISPSD ’01. Proceedings of the 13th International Symposium on Power Semiconductor Devices, June 4-7, 2001, pp. 3-10.

[12] F. Z. Peng, L. M. Tolbert, F. Khan, "Power Electronics' Circuit Topology - the Basic Switching Cells,” IEEE Power Electronics Educational Workshop, June 16-17, 2005, Recife, Brazil, pp. 52-57.

[13] S. Khomfoi, L. M. Tolbert, "Fault Diagnosis and Reconfiguration System for a Multilevel Inverter Drive Using a Principal Component Neural Network,” IEEE Power Electronics Specialists Conference, June 18-22, 2006, Jeju, Korea.

[14] L. M. Tolbert, T. J. King, B. Ozpineci, J. B. Campbell, G. Muralidharan, D. T. Rizy, A. S. Sabau, H. Zhang, W. Zhang, X. Yu, H. F. Huq, H. Liu, "Power Electronics for Distributed Energy Systems and Transmission and Distribution Applications: Assessing the Technical Needs for Utility Applications,” ORNL/TM-2005/230, Oak Ridge National Laboratory, December 2005. 